\title{
Extensively Drug-resistant Tuberculosis Strains in National Tuberculosis Reference Laboratory Between 2005 And 2010, Turkey
}

Ismail Ceyhan ${ }^{1 *}$, Hülya Simsek², Ahmet Arslanturk², Nurhan Albayrak², Figen Sezen ${ }^{3}$ and Gülnur Tarhan ${ }^{4}$

${ }^{1}$ Ataturk Chest Disease and Chest Surgery Training and Research Hospital. Ankara, Turkey

${ }^{2}$ National Tuberculosis Reference Laboratory, Public Health Institute of Turkey, Ankara, Turkey

${ }^{3}$ Public Health Institute of Turkey, Ankara, Turkey

${ }^{4}$ Medical School, Ahi Evran University, Kırşehir, Turkey

\begin{abstract}
Frequency, rate and trend of extensively drug-resistant [XDR] tuberculosis [TB] in Turkey are not clear and not known very well. In this study, it was aimed to try to determine and to confirm the frequency of XDR-TB strains among Multi-Drug Resistant [MDR] TB cases. A total of 4119 M. tuberculosis strains were analyzed. The strains were collected from 19 TB centers [hospitals or regional TB laboratories] including National TB Reference Laboratory [NTRL]. Two hundred ninety-seven 297 [7.2\%] M. tuberculosis strains were detected as MDR-TB. Among all MDRTB cases, 37 [12.5\%] were pre-XDR-TB, and 8 [2.7\%] were XDR-TB.
\end{abstract}

Keywords: Extensively drug resistant tuberculosis; Multidrug resistant tuberculosis; Tuberculosis

\section{Introduction}

TB is one of the oldest known infectious diseases, and today still remains an important health problem both worldwide and in our country. World Health Organization [WHO] estimates that one third of world's population is infected by $M$. tuberculosis. There were nearly 8.6 million cases around the world in 2012 and approximately 1.3 million of them died. TB incidence was 122 per 100,000 population, while global TB prevalence was 169 per 100,000 population in 2012 [1]. According to the 2012 report of TB Control Department in Turkey, the number of cases registered in 2010 was 16551 and TB incidence was 24 per 100000 population, while the number of new cases was 15183 [2]. In recent years, a dramatic increase in the emergence of MDR-TB and XDR-TB cases has been observed. Globally drug resistance is a major concern for global health [1,3-6]. MDR-TB has been documented in most of the countries and regions and at least one XDR-TB has been reported in 68 countries until February 2011 [7].

$\mathrm{XDR}-\mathrm{TB}$ has been identified as a significant problem in countries of the former Soviet Union [8] and the potential threat of XDR-TB for Europe has been assessed by the European Centre for Disease Centre and Prevention [ECDC] in 2006 [9]. The WHO Global Task Force on XDR-TB has recommended laboratory-based surveillance to better understand the prevalence of XDR-TB in developing countries [10]. It has not been yet notified officially of XDR-TB cases in Turkey. There are some studies on drug resistance including several geographic areas of Turkey. These studies are not comprehensive and outcome-based data have some significant limitations. There is no reliable survey to be representative of the population throughout the country. However, it has been started laboratory based surveillance by NTRL in recent years. In the this study, we aimed to analyze our laboratory data and to try to determine the frequency of XDR-TB strains among MDR-TB cases during six year-period from 2005 to 2010 in Turkey.

\section{Materials and Methods}

In the present study, M. tuberculosis complex strains which were isolated from National TB Reference Laboratory [NTRL] and from Regional TB laboratories and 19 TB centers located in some major cities and towns in Turkey between 2005-2010 were examined. NTRL routinely accepts cultures for further tests such as strain typing and drug susceptibility testing [DST]. Specimens for TB cultures are requested by physicians as defined by TB control department. Treatment history was almost always not available and therefore was not included in the study. Due to the fact that DST is routinely performed in Turkey as standard patient care, no ethical approval was required for this study. Internal quality control was routinely performed during DST using reference strain M. tuberculosis $\mathrm{H} 37 \mathrm{Rv}$, and the expected results were always obtained. External quality assurance for first-line drugs was performed by the Supranational Laboratory Network of the WHO with satisfactory results. Quality assurance procedures for second-line drug susceptibility testing were not defined or developed by the Supranational Laboratory Network; thus, as a proxy for quality assurance, we studied the accuracy of second-line DST among isolates susceptible to the first-line drugs [11]. M. tuberculosis was isolated from the specimens by using Lowenstein-Jensen, Ogawa and/or MGIT [Becton Dickinson, Franklin Lakes, NJ, USA] media. It was then identified by using NAP-TB differentiation test [Becton Dickinson] and growth in para-nitrobenzoic acid containing medium [12]. We performed susceptibility testing by using a modified proportion method in which drug containing LJ media at the following concentrations were used: rifampicin [RIF] 40 $\mu \mathrm{g} / \mathrm{mL}$, isoniazid [INH] $0.2 \mu \mathrm{g} / \mathrm{mL}$ and $1 \mu \mathrm{g} / \mathrm{mL}$, streptomycin [SM] $4 \mu \mathrm{g} / \mathrm{mL}$, and ethambutol [EMB] $2 \mu \mathrm{g} / \mathrm{mL}$ [13]. MDR-TB strains were further tested with second-line drugs, such as capreomycin $40 \mu \mathrm{g} / \mathrm{mL}$, ofloxacine $2 \mu \mathrm{g} / \mathrm{mL}[13,14]$ amikacin $40 \mu \mathrm{g} / \mathrm{mL}$ [13], kanamycin $30 \mu \mathrm{g} /$ $\mathrm{mL}$ and ethionamide/protionamide $20 \mu \mathrm{g} / \mathrm{mL}$ [14]. Reference strain $M$. tuberculosis $\mathrm{H} 37 \mathrm{Rv}$ was used as a control with each susceptibility testing batch. MDR-TB is defined as TB resistant to the two most important antituberculosis drugs, INH and RIF. XDR-TB refers to TB resistant to

*Corresponding author: Ismail Ceyhan, Ataturk Chest Disease and Chest Surgery Training and Research Hospital, Chief of Microbiology and Hematology Laboratory, B Blok Ankara, Turkey, Tel: +90 [312] 56770 00; E-mail: isceyhan@gmail.com

Received January 08, 2014; Accepted January 25, 2014; Published February 01, 2014

Citation: Ceyhan I, Simsek H, Arslanturk A, Albayrak N, Sezen F, et al. (2014) Extensively Drug-resistant Tuberculosis Strains in National Tuberculosis Reference Laboratory Between 2005 And 2010, Turkey. Clin Microbial 3: 136. doi:10.4172/2327-5073.1000136

Copyright: ( 2014 Ceyhan I, et al. This is an open-access article distributed under the terms of the Creative Commons Attribution License, which permits unrestricted use, distribution, and reproduction in any medium, provided the original author and source are credited. 
at least INH and RIF, as well as to two of the most effective second-line drugs: a fluoroquinolone and at least one of the second-line injectable agents [amikacin, capreomycin, or kanamycin] [4]. Pre-XDR TB was defined as TB with resistance to isoniazid and rifampin and either a fluoroquinolone or second-line injectable agent but not both [15].

\section{Results}

Between 2005 and 2010, 4119 cultures were identified as $M$. tuberculosis complex strains from pulmonary TB cases and DST for 4119 strains was performed. While 297 [7.2\%] of 4119 M. tuberculosis strains were detected as MDR-TB, 3270 strains were susceptible to all drugs. Ninety three [2.2\%] strains were resistant to all first-line anti TB drugs. The numbers of resistant strains to SM, INH, RIF and ETB were 459 [11.1\%], 539 [13.1\%], 389 [9.4\%], and 229 [5.6\%], respectively. Of 297 [7.2\%] multi drug resistant M. tuberculosis strains, 8 [2.7\%] were extensively drug resistant according to laboratory data. During the six year-period the rates of MDR- and XDR-M. tuberculosis varied from $5.9 \%$ to $7.9 \%$ and from $0 \%$ to $6.5 \%$ respectively (Table 1 ).

\section{Discussion}

The number of the resistant to second-line drugs of $M$. tuberculosis strains is increasing and to threat of MDR-TB are becoming a public health problem worldwide. This problem is man made $[3,16]$ and it has been creating by wrong intervention such as poor prescribing practices, low drug quality [or erratic supply], and suboptimal adherence [17]. The fact that both XDR-TB and MDR-TB cases have recently been observed commonly in the world and it has been increased in the failure of TB treatment $[3,16,18]$. Early diagnosis and detection of resistant strains by using qualified DST facilitates introduction of an appropriate drug regimen $[15,19,20]$, other protective measures and preventive activities [21,22].

The WHO estimated the annual burden of MDR-TB to be around 650,000 cases [1] and the prevalence of MDR-TB to be significantly higher than the annual incidence, primarily in low and middleincome countries $[1,8]$. MDR strains are currently found in more than
$15 \%$ of all new cases of TB in some areas of the former Soviet Union [Azerbaijan, Moldova, Ukraine and Tomsk Oblast], and in more than $10 \%$ in parts of China and other areas of the former Soviet Union [Latvia, Estonia, Kazakhstan, Uzbekistan, andIvanovo and Mari El [both Russian Federation] $[8,23,24]$ In contrast, MDR TB in Western Europe countries with good national control programs such as Italy, is not a major health problem [25].

According to the official report of TB Control Department in Turkey, the number of cases registered in 2010 was 16,551 and TB incidence was 24 per 100,000 population, while the number of new cases was 15,183 . National data on treatment outcomes for cases of MDR-TB are limited and all of these cases were not confirmed by DST in TB laboratories. MDR-TB cases reported by TB Control department between 2005 and 2009 were 191, 249, 240, 263 and 222 respectively. In 2010, 250 MDR-TB cases [5\%] were detected among 4965 cases which had had DST results. Officially, no XDR-TB case was reported [2].

Until now, studies on drug resistance in Turkey have included several geographic areas around the country. However, most of these areas presented significant biases, because outcome-based measures have some significant limitations [different studies, methods, and population involved] resulting high degrees of variability between resistance levels among different settings. There is no reliable survey to be representative of the population throughout the country [26-35]. One of the first studies about drug-resistant TB in Turkey was reported by Bengisun et al. in 2000. The study retrospectively evaluated the resistance of 3319 $M$. tuberculosis strains to primary anti-tuberculosis drugs over the 21 year-period 1976-97. It was found that $60.8 \%$ of the isolates were susceptible, whereas $39.2 \%$ were resistant to at least one drug. MDR-TB was found in 194 [5.8\%] cases [26]. Another study on resistance was reported by Senol et al. in 2005. The data were retrospectively collected by searching records of $\mathrm{TB}$ division of microbiology laboratory between 1999 and 2001. A total of 5084 TB cases were evaluated and MDR-TB rate was found to be $6.2 \%$ [27]. The other several studies showed that MDR-TB rates in Turkey varied from $3.2 \%$ to $14.7 \%$ (Table 2), while the

\begin{tabular}{|c|c|c|c|c|c|}
\hline Year & $\begin{array}{c}\text { Number of } M . \text { tuberculosis } \\
\text { isolates }\end{array}$ & Number of MDR* isolates, (\%) & $\begin{array}{c}\text { Number of Pre-XDR }{ }^{*} \text { isolates, } \\
(\%)\end{array}$ & Total Number of XDR isolates & $\begin{array}{c}\text { XDR as } \% \text { of total } \\
\text { MDR }\end{array}$ \\
\hline 2005 & 644 & $47(7.3)$ & $5(10.6)$ & 0 & 0 \\
\hline 2006 & 716 & $42(5.9)$ & $3(7.1)$ & 2 & 4.8 \\
\hline 2007 & 636 & $50(7.9)$ & $7(14.0)$ & 2 & 4.0 \\
\hline 2008 & 670 & $53(7.9)$ & $4(7.5)$ & 0 & 0 \\
\hline 2009 & 638 & $46(7.2)$ & $14(30.4)$ & 3 & 6.5 \\
\hline 2010 & 815 & $59(7.2)$ & $4(6.8)$ & 1 & 1.7 \\
\hline Total & 4119 & $297(7.2)$ & $37(12.5)$ & 8 & 2.7 \\
\hline
\end{tabular}

"MDR: multidrug resistant; " XDR: extensively drug resistant.

Table 1: MDR and XDR M. tuberculosis isolates, in a six year period from 2005 to 2010.

\begin{tabular}{|l|c|c|c|}
\hline Authors (Reference) & City/Region(s) & Period of study & $\begin{array}{c}\text { M. tuberculosis cases/strains } \\
\text { MDR rates (\%) }\end{array}$ \\
\hline Bengisun JS, et al. [26] & Ankara & $1976-1997$ & 3319 \\
\hline Şenol G, et al. [27] & Izmir & $1999-2001$ & 5084 \\
\hline Saral ÖB, et al. [28] & Trabzon & $1998-2004$ & 442 \\
\hline Özekinci T, et al. [29] & Diyarbakir & $2001-2003$ & 100 \\
\hline Erturan Z, et al. [30] & Istanbul & $1992-2002$ & 1843 \\
\hline Uçar E, et al. [31] & Seven regions of Turkey & $2003-2006$ & 1091 \\
\hline Karabay O, et al. [32] & Edirne & 2004 & 214 \\
\hline Karadağ A, et al. [33] & Samsun & 2004 & 5.9 \\
\hline Gönlügür U, et al. [34] & Sivas & $2004-2006$ & 50 \\
\hline Aydın F, et al. [35] & Trabzon & Jan. 2005-Mar. 2010 & 158 \\
\hline
\end{tabular}

Table 2: Reports of studies on M. tuberculosis resistance in Turkey (1974-2010). 
Citation: Ceyhan I, Simsek H, Arslanturk A, Albayrak N, Sezen F, et al. (2014) Extensively Drug-resistant Tuberculosis Strains in National Tuberculosis Reference Laboratory Between 2005 And 2010, Turkey. Clin Microbial 3: 136. doi:10.4172/2327-5073.1000136

XDR-TB rate from 2005 to 2010 was variable without any evidence of increasing (Table 1).

\section{Conclusions}

Despite the existence of Directly Observed Treatment Strategies [DOTS] and TB Control program, Turkey couldn't exclude the problems of emergence of drug-resistant M. tuberculosis strains.

The present study which was conducted from 2005 to 2010 demonstrated that there is no evidence of raising of XDR-TB cases in 19 defined centers in Turkey. Statistical analysis could not apply, due to low numbers of XDR-TB cases in this study. Average rates were $7.2 \%$ for MDR-TB and 2.7\% for XDR-TB which was below the global XDR-TB average [6.6-23.7\%] [36].

The results discussed in this study suggest that Turkey needs to strengthen strategies to prevent the emergence of new drug-resistant $M$. tuberculosis strains, not only for MDR-TB, but also for XDR-TB cases.

Study limitations include unavailability of data to assess trends in specimen collection practices, so we could not evaluate how specimen collection practices may have influenced the increase in reporting of MDR-TB over time. Also the data were unavailable for categorizing MDR-TB cases as new or retreatment. Therefore, it is necessary and urgent to estimate the magnitude of the resistance of $M$. tuberculosis at a national level in order to evaluate the progress of DOTS under recent health care reforms. According to WHO/IUATLD [7], NTRL has started a sub nationwide survey [Ankara, 2011, and Istanbul, 2012] and has been tested to test MDR-TB isolates for second-line drug resistance. NTRL has established capacity to perform survey by technical coordination and cooperation with Supranational Tuberculosis Reference Laboratory in Italy. This survey will be a priority to consider the future management of MDR-TB and XDR-TB in Turkey.

\section{Summary}

In this retrospective study, our results suggest that Turkey needs to strengthen strategies to prevent the emergence of drug-resistant $M$. tuberculosis strains, not only for MDR-TB, but also for XDR-TB.

\section{References}

1. World Health Organization. Global tuberculosis control: WHO Report 2013 Publication no. WHO/HTM/TB/2013.11. Geneva 2013

2. Ministry of Health (2012) TB Control Department, Türkiye'de Verem Savasi 2012 Raporu (Report of Tuberculosis Control in Turkey).

3. Gandhi NR, Nunn P, Dheda K, Schaaf HS, Zignol M, et al. (2010) Multidrugresistant and extensively drug-resistant tuberculosis: a threat to global control of tuberculosis. Lancet 375: 1830-1843.

4. Prasad $R$ (2010) Multidrug and extensively drug-resistant $T B(M / X D R-T B)$ : problems and solutions. Indian J Tuberc 57: 180-191.

5. Jain A, Dixit P (2008) Multidrug-resistant to extensively drug resistant tuberculosis: what is next? J Biosci 33: 605-616.

6. Shah NS, Wright A, Bai GH, Barrera L, Boulahbal F, et al. (2007) Worldwide emergence of extensively drug-resistant tuberculosis. Emerg Infect Dis 13: 380-387

7. World Health Organization. Countries that had reported at least one XDR-TB case by end of 2010 .

8. World Health Organization. Anti-tuberculosis resistance in the world. Report no. 4.Geneva: The Organization; 2008.

9. Migliori GB, Pai M, Matteelli A, Cirillo D (2007) Extensive drug-resistant TB: a threat for Europe. European Infec Dis 115-18

10. World Health Organization (2012) The Global Task force onXDR-TB.
11. Elder BL, Hansen SA, Kellogg JA, Marslk FJ and Zabransky RJ (1997) Venflcatlon and Valldatlon of Procedures in the Clinical Mlcrobiology Laboratory. Coordinating McCurdy BW (ed.). Amencan Society for Microbiology, Washington, DC, USA

12. Koneman EW, Dowell VR, Sommers HM (1983) Color atlas and text book of diagnostic microbiology. JB Lippincott Company, Philadelphia, USA.

13. European Centre for Disease Prevention and Control (2011) Mastering the basics of TB control: Development of a handbook on TB diagnostic methods. ECDC, Stockholm, Sweden.

14. World Health Organization. Guidelines for Drug Susceptibility Testing for Second-Line Anti-Tuberculosis drugs for DOTS-Plus. WHO/CDS/TB/2001.288

15. Banerjee R, Allen J, Westenhouse J, Oh P, Elms W, et al. (2008) Extensively drug-resistant tuberculosis in california, 1993-2006. Clin Infect Dis 47: 450-457.

16. Loddenkemper R, Hauer B (2010) Drug-resistant tuberculosis: a worldwide epidemic poses a new challenge. Dtsch Arztebl Int 107: 10-19.

17. Lawn SD, Wilkinson R (2006) Extensively drug resistant tuberculosis. BMJ 333 : 559-560.

18. TB alliance, MDR-TB/XDR-TB.

19. Kwon YS, Kim YH, Suh GY, Chung MP, Kim H, et al. (2008) Treatment outcomes for HIV-uninfected patients with multidrug-resistant and extensively drug-resistant tuberculosis. Clin Infect Dis 47: 496-502.

20. Cox H, McDermid C (2008) XDR tuberculosis can be cured with aggressive treatment. Lancet 372: 1363-1365.

21. Bayona J, Chavez-Pachas AM, Palacios E, Llaro K, Sapag R, et al. (2003) Contact investigations as a means of detection and timely treatment of persons with infectious multidrug-resistant tuberculosis. Int J Tuberc LungDis 12: S501-

22. Cain KP, Nelson LJ, Cegielski JP (2010) Global policies and practices for managing persons exposed to multidrug-resistant tuberculosis. Int $\mathrm{J}$ Tuberc Lung Dis 14: 269-274.

23. Espinal MA, Laszlo A, Simonsen L, Boulahbal F, Kim SJ, et al (2001) Global trends in resistance to antituberculosis drugs. World Health Organization/ International Union against Tuberculosis and Lung Disease Working Groupon Anti-Tuberculosis Drug Resistance Surveillance. N Engl J Med 344: 1294-1303.

24. Raviglione MC, Uplekar MW (2006) WHO's new Stop TB Strategy. Lancet 367: 952-955.

25. Migliori GB, Centis R, Fattorini L, Besozzi G, Saltini C, et al. (2004) Mycobacterium tuberculosis complex drug resistance in Italy. Emerg Infect Dis 10: $752-753$

26. Bengisun JS, Karnak D, Palabiyikoglu I, Saygun N (2000) Mycobacterium tuberculosis drug resistance in Turkey, 1976-97. Scand J Infect Dis 32: 507510.

27. Senol G, Komurcuoglu B, Komurcuoglu A (2005) Drug resistance of Mycobacterium tuberculosis in Western Turkey: a retrospective study from 1100-bed teaching hospital. J Infect 50: 306-311.

28. Saral OB, Sucu N, Boz GA, Erdem M, Koksal Đ (2007) 442 Mycobacterium tuberculosis susunda BACTEC yontemi ile kombine ilac direncinin arastirilmasi. Tur Toraks Der; 8: 174-178.

29. Özekinci T, Özbek E, Gedik M, Temiz H., Atmaca S (2006) Drug resistance of Mycobacterium tuberculosis strains isolated between 2001-2003. Türk Mikrobiyol Cem Derg 36: 31-34

30. Erturan Z, Uzun M, Satana D, Yegenoglu Y. Drug resistance patterns of Mycobacterium tuberculosis complex strains isolated during an eleven year period in a faculty hospital in Istanbul. Biotechnol \& Biotechnol.

31. Uçar E, Kiliç A, Ceyhan I, Yilmaz S, Kiliç S, et al. (2010) [Resistance rates to major anti-tuberculosis drugs in Mycobacterium tuberculosis strains isolated from seven different regions of Turkey in 2003-2006 period]. Mikrobiyol Bul 44: $11-19$

32. Karabay O, Otkun M, Akata F, Karlikaya C, Tuğrul M, et al. (2004) Antituberculosis drug resistance and associated risk factors in the European section of Turkey. Indian J Chest Dis Allied Sci 46: 171-177.

33. Karadag A, Tokaç M, Güvenli A, Sünbül M, Günaydin M and Saniç A (2004) Klinik örneklerden izole edilen tüberküloz basili kompleksinin majör ilaçlara direnç oranlari. ANKEM Derg 18: 189-192. 
Citation: Ceyhan I, Simsek H, Arslanturk A, Albayrak N, Sezen F, et al. (2014) Extensively Drug-resistant Tuberculosis Strains in National Tuberculosis Reference Laboratory Between 2005 And 2010, Turkey. Clin Microbial 3: 136. doi:10.4172/2327-5073.1000136

Page 4 of 4

34. Gönlügür U, Bakici MZ, Gönlügür TE, Hasbek M (2007) [Resistance rates to antituberculous drugs in Sivas province]. Mikrobiyol Bul 41: 459-463.

35. Aydın F, Kaklıkkaya N, Bayramoğlu G, Ozkul G, Buruk K, et al. (2011) [Resistance rates of Mycobacterium tuberculosis complex strains isolated from clinical specimens]. Mikrobiyol Bul 45: 36-42.
36. Wright A, Zignol M, Van Deun A, Falzon D, Gerdes SR, et al. (2009) Epidemiology of antituberculosis drug resistance 2002-07: an updated analysis of the Global Project on Anti-Tuberculosis Drug Resistance Surveillance. Lancet 373: 1861-1873. 